\title{
A short history of studies on intelligence and brain in honeybees
}

\author{
Randolf MENZEL \\ Berlin, Germany \\ Received 20 February 2020 - Revised 24 June 2020 - Accepted 21 July 2020
}

\begin{abstract}
Reflections about the historical roots of our current scientific endeavors are useful from time to time as they help us to acknowledge the ideas, concepts, methodological approaches, and idiosyncrasies of the researchers that paved the ground we stand on right now. The 50-year anniversary of Apidologie offers the opportunity to refresh our knowledge about the history of bee research. I take the liberty of putting the founding year of Apidologie in the middle of the period I cover here. The nascent period of behavioral biology around the late 19th to the early twentieth century was intimately connected with a loss of concepts related to the mental functions of the brain, concepts that were rooted in Darwin's theory of gradualism in the living world including cognition in animals. This loss was celebrated both in ethology and behaviorism as the gateway to scientific impartiality. Using this apparently strict scientific approach, impressive discoveries were made by observing and strictly quantifying the behavior of bees. The first forays into the brain, however, uncovered a richness of structure and function that reached far beyond stereotypical input/output connections and opened the way to compensating the conceptual restrictions imposed on us by traditional ethology. Honeybee research provides us with a particularly exciting story in this context. The cognitive turn in behavioral biology is intimately connected to the increasing knowledge of how the brain works, also in honeybee research. What has been achieved so far is just the beginning, but it gives us a glimpse of a promising future. Teamwork between neuroscientists and behavioral biologists is needed to elucidate brain functions such as the expectation of future outcomes and intentionality as an entry to animal intelligence reflecting the flexibility and adaptability in behavior also seen in honeybees.
\end{abstract}

honeybees / intelligence / brain

\section{INTRODUCTION}

At the time the journal Apidologie was founded, behavioral biology was comfortably embedded in two parallel, rather independent streams of thinking — ethology and experimental psychology (behaviorism, Pavlovian psychology). Although there were considerable battles between the two disciplines, each found itself on a conceptually firm foundation. Ethologists preferred to

Corresponding author: R. Menzel,

menzel@neurobiologie.fu-berlin.de

This article is part of the Topical Collection on the

Apidologie 50 Years

Handling Editor: Monique Gauthier look into natural behavior in the species-specific environment and selected those behaviors that could be released or induced reliably multiple times (Tinbergen 1951; Thorpe 1979). Behaviorists worked preferably in the lab creating conditions that led to repeatable test conditions using classified training schemes (Skinner 1988). Although the research strategies and terminology were very different between the two disciplines, they had a shared understanding that interpretive or intervening terms, particularly those that included hidden reference to brain functions, were to be avoided or even banned. Rollin (1990) characterized this attitude convincingly as "how animals lost their minds". Furthermore, an additional common ground of both schools was 
their harsh opposition to any form of "anecdotal cognitivism" and anthropomorphism (Jamieson and Bekoff 1996) as entertained by nineteenth century zoologists including Darwin (see exemplary cases below). This victory over the "unscientific attitudes of the past century" was celebrated whenever the debate about the differences between the two schools became too complicated and when doubts appeared about their respective conceptual delimitations emerged.

Insects were thought to naturally belong to the realms of ethology, because their behavior was obviously dominated by innate and rather stereotypical routines. Furthermore, insects have small brains, and thus, cognitive aspects could be more easily dismissed. Von Frisch (1962, p. 78) somewhat apodictically stated: "The brain of a bee is the size of a grass seed and is not made for thinking. The actions of bees are mainly governed by instinct". There are several reasons why we should be surprised by von Frisch's statement. Von Frisch was a highly informed naturalist and evolutionary biologist. He certainly knew Darwin's (1859) position, as expressed, for example, in the following statements taken from The origin of species by means of natural selection or the preservation of favored races in the struggle for life: "... there may be extraordinary mental activity within an extremely small absolute mass of nervous matter: thus the wonderfully diversified instincts, mental powers, and affections of ants are notorious, yet their cerebral ganglia are not so large as the quarter of a small pin's head." And "There is no fundamental difference between man and the higher animals in their mental faculties" (p. 448). He claimed that "the lower animals, like man, manifestly feel pleasure and pain, happiness, and misery." (p. 448). And: "If no organic being excepting man had possessed any mental power, or if his powers had been of a wholly different nature from those of the lower animals, then we should never have been able to convince ourselves that our high faculties had been gradually developed. But it can be shown that there is no fundamental difference of this kind. We must also admit that there is a much wider interval in mental power between one of the lowest fishes, as a lamprey or lancelet, and one of the higher apes, than between an ape and a man; yet this interval is filled up by numberless gradations." (p. 445).

Ethologists like von Frisch might have argued that insects and arthropods in general followed an evolutionary branch too remote from that of mammals and primates, and thus, their behavioral strategies of coping with the demands of the environment involved basically different adaptations, as for example specialized sense organs and highly tuned adaptations of adjusting instinctive responses (see below). We might also be surprised about von Frisch's statement because he developed the training method for bees to perfection, documenting with each experiment how flexible the bees' behavior is. While applying these methods, he discovered the honeybee's most impressive behavior (the waggle dance), which clearly cannot be thought of as an instinctive behavior at all since it is a communication process which is based on learned flight routes embedded in the memory about the explored environment (see below). There is also a third reason why we should be surprised about von Frisch's statement. The brain of the honeybee although tiny was wonderfully described as early as the mid-nineteenth century (Dujardin 1850; Kenyon 1896), and the volume of the whole brain or parts of it (the mushroom body) was related to the social life and the complexity of behavior in solitary and social Apoidea (von Alten 1910) indicating an intrinsic structure that is adapted to its functions.

I have referred to Karl von Frisch at the outset of this review because he is the most eminent honeybee researcher of the last century, and also because I had the privilege of talking to him (though only briefly) in 1965. Obviously, we have to reach beyond the last 50 years of honeybee research in order to better understand the conceptual framework in which behavioral and neurobiology developed in the first and the second half of the twentieth century.

\section{ARE BEES INTELLIGENT, AND WHAT IS INSECT INTELLIGENCE?}

Although nineteenth century naturalists and honeybee lovers were excellent observers, they were criticized for two inexcusable failures: 
reporting only single case events and using unjustified anthropomorphic terminology. Indeed, repetitions under strict experimental control were rarely performed, and, if so, the conditions were not reported. Anthropomorphic terminology was not considered misleading or dangerous because Darwin's gradualism guided the comparative approach in behavioral studies as in comparative morphology. Reading this literature gives the strong impression that the authors, such as Romanes (1883), Forel (1910), Buttel-Reepen (1900), and even Maeterlinck (1901) with his romantic style in praise of the honeybee, did not mean mental operations of a human kind when they used terms like intelligence or mental power, but rather species-specific forms of such operations, although all of these authors kept their meaning vague.

Here are three examples of these early endeavors into honeybee intelligence. (1) Is there a measure of insect intelligence? "Sir John Lubbock is very much inclined to deny bees all powers of discrimination and all deliberation,... As proof he provides an experiment that anyone can easily repeat. Put half a dozen flies and the same number of bees in a water bottle, lie the bottle down horizontally and turn it so that the bottom of the bottle faces the window of the room. The bees will struggle for hours to find a way out through the glass bottom before they finally die of exhaustion and hunger, whilst the flies have escaped to the opposite side through the neck of the bottle in less than two minutes. Sir John Lubbock concludes that the bee's brain is extremely limited and that the fly is much better equipped to solve this dilemma and find the way out... What lets the bees down in the experiment of this English scholar is their love of light and their intellect itself. They evidently surmise that the escape route from every prison is on the light side; so the bee is acting logically, only too logically." (Maeterlinck 1901, p. 85). Quantifying intelligence has been an obsession in the nineteenth century including reference to brain size and volumes of particular brain structures (see e.g. for humans: Mackintosh and Mackintosh 2011, insects: Romanes 1883; von Alten 1910). Maeterlinck's further discussion (not cited here) is helpful in this context because he criticized not only the ignorance of species- specific adaptations but also the quantification process itself. Similar doubts were raised much later with respect to learning functions and memory span and brain size (Rensch 1954).

Learning during departure. "As the bee takes off she turns her head towards the hive and, while continuously hovering up and down, she inspects in detail the hive itself, the neighboring hives and the hive stand, all the while directing her eyes towards the hive. Only after this prelude are first small and then ever-increasing orientation circles traced and thereby the immediate and more distant surroundings memorized" (Buttel-Reepen 1900, p. 41). Maeterlinck (1901) described a similar situation with these words: "As soon as this vessel (the honey stomach) is filled, the bee flies away from that place, but not blindly and directly like a butterfly or a fly. On the contrary, one will see her fly backwards for a few moments; she buzzes attentively in the window opening or around the table, her head facing into the room. She memorizes the place and notes exactly where the treasure lies. Only then does she fly back to the hive ....." (p. 93). Buttel-Reepen (1900) transported young bees before their orientation flights and those after completing orientation flights to release sites further away from the hive and found that only the latter returned home. Full proof for the notion that bees learn during departure from the hive or the feeding place were provided only much later in well-controlled experiments (Opfinger 1931; Lehrer 1991). The study of these "learning flights" provided multiple insights into visual matching procedures of honeybees, bumble bees, solitary bees, and wasps (Collett 1995; Zeil 1993; Zeil et al. 1996; Collett et al. 2013).

Social communication. "Finally, in order to get a better idea of their intelligence, we would have to try to determine how they communicate with each other. ... So they must have the ability to express their thoughts and feelings, be it through a spoken language or, more likely, with the help of a tactile language or magnetic transmission, which perhaps is linked to the properties of the material and to senses that are completely unknown to us, and the seat of these senses could be located in their mysterious feelers.... Once I applied a splash of color to the body of an Italian bee. The second time she came back with two companions. I captured these without 
bothering them. The next time she came back with three companions, which I also caught, and so on, until at the end of the afternoon I had captured 18 bees. So she had known how to pass on the information to 18 companions... Do those companions that turn up at the treasure trove discovered by the first bee do nothing more than to follow her, or are they perhaps sent by her and find the reward themselves using her information and her description of the location? If this were the case, as one can easily see, there would be a huge difference in the level and perfection of their intelligence.... I took an Italian bee from an observation hive located not far from the house, carried it up to my study, and allowed it to nibble on the honey while I dabbed it with a splash of color. Once the bee had sucked her fill, she flew back to the hive. I followed and saw how she ran hastily over the other bees, stuck her head into an empty cell, emptied the honey, and prepared to fly out." (Maeterlinck 1901, p. 95 - 98). Maeterlinick continued by describing how he tried to prove the hypothesis that the new bees did not follow the trained bee but rather received a message about the location and sadly acknowledges that he was not successful. It was von Frisch who succeeded. He also marked a bee that had brought back a newcomer and, in 1919, observed for the first time the waggle dance. He noted in his "Recollections of a Biologist" ("Erinnererung eines Biologen", von Frisch 2013, p. 45 and 60) that he first observed a form of recruitment by the trained bees during his color (1912) and later during his odor (1918) discrimination experiments and expressed his surprise: "I couldn't stop thinking about it." In 1919 he used an observation hive housing a small colony from which he trained bees to a feeding site for odor discrimination. "I lured a number of bees to a dish with sucrose solution, dabbed them with red oil paint and switched to a feeding pause. ....I couldn't believe my eyes. She (a scout bee) performed a round dance on the comb which caused great excitement among the red-marked foragers around her, and prompted them to fly back to the feeding place. That was probably the most momentous observation of my life." It took von Frisch and his co-workers nearly 50 years of intense and ingenious work to unravel the mystery of the waggle dance (von Frisch 1967).

These three examples nicely illustrate that the nineteenth century naturists were excellent observers and posed the right questions, but the contrast to the twentieth century was substantial. The anthropomorphic wording did not restrain their curiosity about unresolved questions and was not used, as often assumed, as an explanation for the observed phenomena. Still, compared with the advances achieved primarily by the von Frisch school in the first half of the twentieth century, the limitations are obvious. Von Frisch succeeded because he installed a training procedure that allowed multiple repetitions of discrimination tests under strictly controlled conditions, quantification of the choice behavior, and separation between trained and untrained bees (von Frisch 1914). In addition, in 1919, he introduced a method for marking bees individually, an experimental procedure whose impact on all subsequent studies in honeybees since then cannot be overestimated (von Frisch 1919). Against the background of these advances, reports by nineteenth century behavioral biologists have to be considered as predominantly but not completely anecdotal and in most cases lacking proper quantification. The story-telling approaches were replaced by the essentials of any modern enterprise in the natural sciences, the clear separation between hypothesis, data, and interpretation. Behavioral biology joined the life sciences as an independent and flourishing scientific branch. The parsimony argument (also called Occam's razor or Lloyed Morgan's canon) was accepted as a guideline in developing overarching concepts, possibly to a degree that became restrictive for new views (see below).

Honeybee behavioral biology had strong roots in what became ethology because the questions arose from studies under rather natural conditions and were motivated by evolutionary considerations. For example, studies on color vision and odor discrimination were motivated by insights into the co-evolutionary relation of pollinating insects and flowers (Sprengel 1793). Similar arguments were applied to behavioral traits in navigation (requirements for safe returns to the nest site), the sense of time as a necessity for using the sun compass in navigation, and social forms of communication as adaptations to improve social life and economy of pollination. However, training techniques and semi-laboratory test conditions were applied in a similar way by experimental 
psychologists, and indeed, one of the first publications of von Frisch dealt with psychological methods in working with bees (von Frisch 1905). So, von Frisch does not fit well in the schematic separation of behavioral biology between 1910 and 1960. The focus on sensory physiological questions including his work on the waggle dance could probably be best described as sensory ethology since he was mostly concerned with understanding honeybee behavior as governed by their sense organs.

The mental world of animals came back into behavioral biology around the time that Apidologie was founded. The elimination of the mind of animals in behaviorism and the descriptive attitude in ethology were increasingly seen as unproductive and inadequate. In this sense, the nineteenth century vibrancy was rekindled. The cognitive turn in ethology can be traced to Darwin's writing emphasizing the continuity of the animals' mental life and the value of comparative studies. Multiple overlapping developments appeared in experimental psychology driven by the insight into the self-imposed conceptual limitations and the rigidity of the experimental designs. In addition, the enormous breakthroughs in neuroscience required novel views on the relation between behavior and its neural substrates. It was not possible anymore to ignore or even ban the cognitive dimensions of the brain's working (Bekoff et al. 2002; Menzel and Fischer 2011).

This "cognitive turn" was exemplified in honeybees by an experimental study of the mechanisms of learning. Two research lines were followed along this cognitive turn in honeybees, one as an extension of the training method introduced by the von Frisch school (review: Menzel and Giurfa 2006a, b) and one based on a laboratory setting, the proboscis extension response conditioning paradigm (PER conditioning), initially introduced by Kuwabara (1957), further explored by Vareschi (1971) in the context of olfactory discrimination tests, and subsequently analyzed against the background of procedures developed over decades in the American tradition of experimental psychology (Bitterman et al. 1983; see also Matsumoto et al. 2012). The highly valuable paradigms developed in experimental psychology during the time since Watson
(1930), Hull (1943), and Skinner (1938) were recognized and introduced into the study of learning in honeybees (review, e.g., by Giurfa and Sandoz 2012). The studies based on the PER paradigm were particularly fruitful in attempts to test the predictive power and the limitations of learning rules like those developed by Rescorla and Wagner (1972), review Giurfa 2003) and in the search for neural correlates of associative learning in the bee brain (reviews: Hammer and Menzel 1995; Menzel 2014). For example, learning of mixtures of odors can be designed such that elementary explanations do not apply. In a negative patterning case, for instance, the bee has to learn to respond to the single stimuli $\mathrm{A}$ and $\mathrm{B}$ but not to their compound $\mathrm{AB}\left(\mathrm{A}+, \mathrm{B}+, \mathrm{AB}^{-}\right)$. Thus, the animal learns that $A B$ has to be different from the linear sum of A and B. An elementary associative account would predict that the animal responds to $\mathrm{AB}$ even stronger than to the learned elements $\mathrm{A}$ and $\mathrm{B}$, but it does not. In a different task, biconditional discrimination, the bee learns to respond to the compounds $\mathrm{AB}$ and $\mathrm{CD}$ but not to the compounds $\mathrm{AC}$ and $\mathrm{BD}(\mathrm{AB}+, \mathrm{CD}+, \mathrm{AC}-$, $\left.\mathrm{BD}^{-}\right)$. Again, solving this problem cannot be explained by rules of elementary associations (Menzel and Giurfa 2006a, b). The instrumental forms of learning in free-flying bees uncovered cognitive dimensions like stimulus generalization (Giurfa et al. 2001) and expectation, e.g., in a matching-to-sample paradigm (Giurfa et al. 1996) or a spatial cuing effect (Eckstein et al. 2013). Over the years, the conceptual limitations of elementary forms of learning were increasingly recognized, and the direction of the research shifted to paradigms addressing configural forms of learning, context-dependent forms of learning, extraction of learning rules, and exploratory forms of learning (review Menzel et al. 2007). The transition from traditional ethology to cognitive ethology is still an ongoing process accompanied by quite a few and only slowly vanishing conflicts.

Let me give one example: the debate about the cognitive map in honeybee navigation (Menzel 2012, 2017). The cognitive explanation of a task, in this case navigation, has the property of bringing together diverse isolated tasks on an integrating level, while non-cognitive explanations assume 
independent sub-functions. Non-cognitive explanations accommodate the experimental procedure because the individual experiment always examines only a small set of parameters or even a single parameter and remains in traditional ethology. Of course, a bee locates a place not only according to its situation relative to the visual objects perceived at the same time but also according to the flight vector to that place, its position in relation to elongated landscape features, the odor traces carried by the wind to the animal, and much more. Navigation, like many other behaviors, is embedded in a diverse parameter field, and it is absolutely imperative for the experimenter to exclude certain parameters and to examine individual ones in isolation. However, this gives rise to the problem that these individual tasks are too quickly viewed in isolation and interpreted as sufficient for each type of navigation.

One important objection to the cognitive explanation of our experiments (Menzel et al. 2005; Menzel et al. 2011) rests on the argument that the novel shortcuts, which can be seen as an indicator for a map-like memory structure (Tolman 1948), are simply the result of a vector addition (Cruse and Wehner 2011). We addressed this argument in an experiment based on the following design. The vector addition argument is based on the fact that the bees perform their novel shortcuts (in earlier experiments, this was the return flight to the hive via the feeding site (Menzel et al. 2005), in later experiments, the direct flight between the learned site and the dance-communicated site (Menzel et al. 2011)) according to the sun compass, since all vectors used for vector addition refer to the sun compass. In order to test this assumption, we would have to rotate the sun vis-à-vis the earth with its landmarks and check whether the animals still perform their novel shortcuts correctly. This rotation of the sun vis-à-vis the earth was achieved by placing the animals under general anesthesia for a period of $6 \mathrm{~h}$. During this time, the bee's internal clock comes to an almost complete standstill and re-adjusts to the correct value only after a number of days (Cheeseman et al. 2012). We found, as expected, that the animals perform their initial vector flight in such a way that they perceive the sun rotated 90 degrees relative to the earth. Then, however, they fly back to their hive directly, just like the control bees (Cheeseman et al. 2014).
This means that they do not use the sun compass for the return flight, neither for the vector addition nor for reading homing flight vectors that might be associated with certain landmarks. The latter is assumed in the model of Cruse and Wehner (2011). In fact, after recognizing the unexpected (actually wrong) landmarks on the vector flight, they must use the spatial arrangement of the landmarks to identify their correct location and then take a novel shortcut flight that ignores the sun compass (and thus all features deduced from it) and orients exclusively according to the arrangement of the landmarks. This behavior, however, cannot be explained without a cognitive map as introduced by Tolman (1948). However, our colleagues also presented two arguments against this interpretation: (1) the animals could, during the short vector flight, correct their internal clocks and thus their sun compass, and (2) they could indeed use the profile of the horizon for navigation (Cheung et al. 2014). These arguments could easily be rejected based on previously published data (Cheeseman et al. 2014).

Intelligence and the brainControversies like this one are hard to finally resolve with behavioral studies only. A decision will ultimately have to come from the understanding of underlying brain processes because the different interpretations of behavioral data refer to very different brain mechanisms. "The hippocampus as a cognitive map" (the title of the famous book by O'Keefe and Nadel 1978) provides a telling story. The discovery of place cells, head direction cells, border cells, grid cells, and a few more types of neurons in the hippocampus terminated the debate initiated by Tolman (1990)'s proposal of a cognitive map in mammals. No behavioral or neurobiologist today would question that mammals navigate according to the spatial relations of landmarks as coded in the hippocampus in addition to other forms of navigation that are often considered to be more simple. No such knowledge is (yet) available for insects. The central complex in the insect brain codes sun compass-related directions (locusts: Homberg et al. 2011, possibly also in Drosophila: Seelig and Jayaraman 2015; Fisher et al. 2019) in neurons that are functionally comparable to head direction cells in mammals, but how (and whether) spatial 
relations of landmarks are coded and stored in the insect brain is unknown. Direct reading of compass directions from the sun azimuth or polarized light pattern is not an essential requirement of navigation in honeybees since bees find their way in reference to learned landmark features only. When the flight direction in relation to landmarks is encoded in the waggle dance (see below), then they need to refer it to the sun compass (von Frisch and Lindauer 1954), but this does not prove the sun compass as an essential component of navigation in flight. It is thus possible that sun compass-related properties as processed in the central complex are of minor importance for in-flight navigation and provide head direction information only. Formal models can be derived from the aerial view of flying insects that relate sun compass directions to ground structures (review: Webb 2019), but it is unknown whether they model neural processes in the insect brain during navigation (e.g., underlying path integration, association of landmark structures with directions, and combining multiple areal views). The key question in the context of a cognitive approach to navigation is whether the memory of the environment, or, to be more precise, the knowledge base of the experienced environment allows the animal to choose between goals and the respective paths towards them. Novel shortcuts as demonstrated in honeybee flight trajectories support such a view, but related neural data do not exist. The waggle dance in honeybees offers a unique avenue into the potential neural organization of deciding between behavioral options, for example between a feeding place known from former experience and a feeding place indicated by a dancing bee. Dance followers decide whether to explore the place reported by the dancer or to return to the place they had experienced before depending on value parameters extracted from the dance and the memory about their old place (Biesmeijer and Seeley 2005). Bees fly shortcuts between these two sites depending on several conditions, e.g., how many dances they had followed, whether these sites were closer or further away and whether the shortcut was shorter or equally long as the return flight to the hive (Menzel et al. 2011). Neural operations based on the retrieval of stored vector information (experienced and dance communicated) or operations on the level of a map-like memory structure require the simultaneous activation of the respective memories (the flight vectors from the hive to the respective site or the representation of the sites in a map-like memory) in such a way that decisions can be made about which site should be chosen, which one should be aimed for first, whether the other site should be approached, or whether the outbound journey should be terminated and the home trip started. The essence of the question whether a bee has a cognitive map is, therefore, not really meant to be related to the neural procedures involved in coding spatial relations but rather whether the neural knowledge base supports decisions between behavioral options, potential behaviors. These options would have to be evaluated on the basis of the expected respective outcomes. So, do bees have expectations and create intentions and where in the brain should we search for neural correlates (Menzel 2017a)?

In 1967, I asked Karl von Frisch where he would expect to find the memory for flowers in the bee brain, and he responded with a skeptical look: "Why in the brain? Isn't it much too small?" With this answer, von Frisch stayed true to himself. In 1959, he wrote: "Insects have - even in relation to their body size - a very unprepossessing brain, not created to reflect or make inventions. They too accomplish astonishing intellectual feats, complex and meaningful actions. But they do not consider what they should sensibly do in any given case. How they should behave, that is essentially something they are born with. Innate behavior, 'instincts,' guide them on their way through life. Tried and tested over thousands of years, inherited through countless generations, instincts only fail when suddenly faced with unfamiliar tasks. They do not need a lot of brain matter because they restrict themselves to just a few tasks. They are designed for the normal case, for which, of course, the circuits of the nervous process in a perfect way." (von Frisch 1959). What is a normal case for a bee? Does it help to make only instinct responsible for solving the task of pollination? The flower market for a pollinator that lives all year round in any temperate climate is too complex to be genetically encoded. Which flower will offer which food at which quantity and quality at which place and at which time is not predicable. The current distribution of ever-changing locations of nectar, pollen, resin, or water needs to be explored 
as well as potential nest sites. Thus, the rules of the environment and the current situation need to be learned, and they cannot be innate. There simply is no normal case.

The brain which does this is indeed small $\left(1 \mathrm{~mm}^{3}\right.$ with less than 1 million neurons), but does size count in this respect? I believe von Frisch meant that it is not only a matter of size but also of difference. Brains that create expectations and intentions are thought not only to contain more neurons but also to organize them in different and more complex ways. Only such brains are thought to represent the world in a way that planning is possible by internally activating a relevant memory independent of external stimulus conditions, recruit expectations, evaluate them, and decide between options. We do not know whether the bee brain lacks such networks, and we have only limited evidence for such networks in the mammalian or human brain (Krain et al. 2006). What we do know, however, is that the bee brain does not seem to be different in any fundamental way from large brains. The working of the networks can be explored with electrophysiological and neural imaging methods. These methods capture the "noise of thinking" in the brain. Christian Morgenstern (1871-1914), a poet well known in Germany, once wrote this aphorism: "Thoughts make noise. Who knows whether thoughts don't also make a very tiny noise that could be picked up by the finest instruments and empirically deciphered (by comparison and experiment)." Here are a few examples. (1) The sensory space is organized like a neural map. Odors are represented in the antennal lobe in overlapping activity patterns of activated glomeruli similar to odor representation in the olfactory bulb of mammals (Joerges et al. 1997). (2) The appetitive value system involved in olfactory learning can be traced to identified neurons that have properties comparable to those found in the ventral tegmentum of the mammalian brain. These similarities include such derived properties as reward expectation and coding of prediction error (Hammer and Menzel 1995; Schultz 2006). (3) The convergence site of highly processed sensory pathways, the mushroom body, is nested in a pathway parallel to the direct sensory-motor connections similar to what is known from the general organization of the mammalian brain (honeybee brain atlas: https://insectbraindb.org/app/species/7 ). (4) Memory contents (e.g., in the olfactory domain) are encoded in patterns of synaptic changes in the mushroom body calyx (Szyszka et al. 2008), similarly to what we know about memory contents stored in the mammalian olfactory bulb (Wilson and Stevenson 2003). Formal models have picked up essential components of such memory matrices (review: Webb 2019). (5) Read-out neurons of the mushroom body code sensory stimuli in multimodal-, experience-, and attention-dependent way (Menzel 2014). Inhibitory feedback neurons to the input of the mushroom body generate a neural error signal after incorrect behavioral responses in addition to their stimulus valuation (Filla and Menzel 2015). Thus, like in the mammalian brain, mushroom body output neurons encode stimulus conditions in combinatorial patterns of excitation and inhibition. These patterns may precede behavioral actions under instrumental and self-induced behavioral conditions (Zwaka et al. 2018; Duer et al. 2015: Paffhausen et al. 2020). Formal models will need to include these properties in attempts.

\section{THE WAGGLE DANCE: AN INTELLIGENT BEHAVIOR?}

Probably the most important discovery of the last century in behavioral biology was the elucidation of the encoding and decoding processes of the waggle dance. The discoverer, Karl von Frisch, struggled with the interpretation of this unique communication process. He frequently emphasized that he used the term "language" as a metaphor but he also insisted: "It would be equally wrong and a denial of the facts if one would place the bees' method of communication on par with the warning calls of many other animals or the similarly simple "communications of social associations." (von Frisch 1953). Indeed, if only a flight instruction were communicated with fixed relations between the waggle run relative to gravity as a measure for the outbound direction relative to the momentary sun azimuth and the distance with the length of the waggle run (or the number of waggles), we would not classify it as an intelligent communication system. The question, therefore, is what is encoded and decoded? 
Encoding and decoding direction does not require a visible sun; landmarks are sufficient (von Frisch and Lindauer 1954; Dyer and Gould 1981). Dances occur at night with correct codes for the feeder trained during the day (von Frisch 1967). Bees dance only after they have explored the environment. Thus, waggle dance communication is a symbolic form of communication based on motor patterns and accompanied stimuli. How should one deal with the question of what is actually communicated at which level of cognition? Von Frisch said in a public talk: "But what about thinking? Can one speak of a symbol even where there is no thought behind it? ... But insects are differently organized. They show no sign of deliberation, no hint of any emotion. And if one wants to argue that we cannot identify what goes on in the ganglion cells behind the chitinarmored brow of a fly, all their actions and omissions are proven to be innate in every detail, given to them as a pre-formed instinctual act that, from their point of view, would not be worth thinking about. And yet, especially in insects, we find the most wonderful examples for the topic of this lecture. I don't mean the web balloon of the fly, but rather the symbolic dances in a colony of bees, which are not only triggers for an action but communicate complex facts and, almost like the words and sentences of our language, give very specific instructions for the action that is to be undertaken. They serve not only as keys to a lock, but rather - if I may stay with the image - they offer the partner a rich view through the open gateway." (von Frisch 1959).

The waggle dance is a true communication process including feedback from the receiver, the dance following the bees. Von Frisch observed begging signals from a dance follower, leading to trophalaxis between dancer and follwer. Short signals stopping the dancer occur also in other conditions, for example in swarms when a scout bee causes another dancing scout bee to terminate its dances for a new nest site (Seeley et al. 2012). Such feedback signals to the dancer are particularly interesting in a context in which both communicating bees have been visiting the same feeder, and one experienced a dangerous situation at the feeder. In such a situation, it can happen that the latter bee produces a stop signal to the dancing bee (Nieh 2010; Jack-McCollough and Nieh 2015). The following bee must have identified an experienced location via the symbolic message and related it to the local qualities of that object, which is a form of mapping solely on the basis of symbolic codes. Object identity and spatial characteristics are thus combined in an object-unique manner.

Indeed, the waggle dance is not a language in the strict sense because it lacks the multitude of symbols necessary for close to unlimited combinatorial patterns; it has no grammar, and the learning component does not include the symbolic code (Menzel 2019). Nevertheless, the symbolically encoded outbound flight vectors are interpreted by the recruit as a location in spatial relations to explored locations (Menzel et al. 2011). Recent experiments have shown in addition that both messages, the flight instruction as a vector and the location, are used by the recruited in their search flights (Menzel et al. subm.). Although no neural correlates of this behavior exist so far, evidence is accumulating that the dance message is embedded in a memory of the environment organized like a cognitive map reporting intentions about a location in the environment (Menzel 2019). In this sense, the waggle dance is an intelligent behavior, though not a language. The dimensions of intelligence involved in this unique communication system need to be probed in the direction of whether there is intentionality on both the sender and the receiver sides (Menzel 2017b).

\section{CONCLUSION}

Intelligence in animals has many facets, but the most important components are forms of learning beyond elementary associations and a memory structure that allows decisions to be made without access to the stimuli-controlling behavior. I have focused here on the life of the worker honeybee outside its social community facing conditions that require her full neural power. The last 50 years have witnessed a shift towards the cognitive components of this behavior. This shift was only possible on the foundations laid by researchers during the first half of the twentieth century, which were nineteenth century. Their research involved the development of new methods, the careful design of experiments, and the quantification of the individual bee's behavior. The initial focus on questions of sensory physiology was highly productive, but the restrictions 
imposed by traditional ethology had to be overcome in order to understand the behavioral richness and flexibility of the foraging bee. As in other disciplines of behavioral biology, an important component of the cognitive shift was the path into the brain, including the discovery of the workings of identified neurons and networks and the neural substrates of memory. Further understanding of the honeybee's intelligence will come from a combined approach to behavior in more natural conditions and the neural processes involved. Exciting experimental procedures are at hand. Optophysiological recordings allow monitoring the spatiotemporal patterns of clusters of neurons down to the resolution of synaptic complexes (Joerges et al. 1997). The miniature size of the bee brain together with its learning capacity under laboratory conditions offers advantages unmet by other animals. The advent of molecular-genetic techniques will revolutionize neuroscience beyond the well-established model systems like C. elegans and Drosophila. Honeybees will be cooperative in these endeavors as they have been over the last 25 years.

\section{FUNDING}

Open access funding provided by Projekt DEAL.

\section{OPEN ACCESS}

This article is licensed under a Creative Commons Attribution 4.0 International License, which permits use, sharing, adaptation, distribution and reproduction in any medium or format, as long as you give appropriate credit to the original author(s) and the source, provide a link to the Creative Commons licence, and indicate if changes were made. The images or other third party material in this article are included in the article's Creative Commons licence, unless indicated otherwise in a credit line to the material. If material is not included in the article's Creative Commons licence and your intended use is not permitted by statutory regulation or exceeds the permitted use, you will need to obtain permission directly from the copyright holder. To view a copy of this licence, visit http://creativecommons. org/licenses/by/4.0/.

Un bref historique des études sur l'intelligence et le cerveau des abeilles. biologie comportementale / histoire / éthologie / behaviorisme / neurosciences. Eine kurze Geschichte der Studien über Intelligenz und
das Gehirn der Honigbienen. Verhaltensbiologie / Geschichte / Ethologie /
Verhaltenspsychologie / Neurowissenschaft.

\section{REFERENCES}

Alten H.V. (1910) Zur Phylogenie des Hymenopterengehirns. Z. Naturwiss 46: 511-590.

Bekoff M., C. Allen, G.M. Burghardt. (2002) The Cognitive Animal: Empirical and Theoretical Perspectives on Animal Cognition. MIT Press, Cambridge,Mass.

Biesmeijer J.C., T.D. Seeley. (2005) The use of waggle dance information by honey bees throughout their foraging careers. Behavioral Ecology and Sociobiology 59(1): 133-142.

Bitterman M.E., R. Menzel, A. Fietz, S. Schäfer. (1983) Classical conditioning of proboscis extension in honeybees (Apis mellifera). Journal of Comparative Psychology 97 : 107-119.

Buttel-Reepen H. (1900) Sind die Bienen Reflexmaschinen? Experimentelle Beiträge zur Biologie der Honigbiene. Arthur Georgi, Leipzig.

Cheeseman J.F., E.C. Winnebeck, C.D. Millar, L.S. Kirkland, J. Sleigh, et al. (2012) General anesthesia alters time perception by phase shifting the circadian clock. Proc. Natl. Acad. Sci U. S. A 109 (18): 7061-7066.

Cheeseman J.F., C.D. Millar, U. Greggers, K. Lehmann, M.D. Pawley, et al. (2014) Way-finding in displaced clock-shifted bees proves bees use a cognitive map. Proc. Natl. Acad. Sci U. S. A 111 (24): 8949-8954.

Cheung A., M. Collett, T.S. Collett, A. Dewar, F. Dyer, et al. (2014) Still no convincing evidence for cognitive map use by honeybees. Proc. Natl. Acad. Sci U. S. A 111 (42): E4396-E4397.

Collett T.S. (1995) Making learning easy: the acquisition of visual information during the orientation flights of social wasps. J. Comp. Physiol. [A] 177 : 737-747.

Collett T.S., N.H. de Ibarra, O. Riabinina, A. Philippides. (2013) Coordinating compass-based and nest-based flight directions during bumblebee learning and return flights. J Exp Biol 216 (Pt 6): 1105-1113.

Cruse H., R. Wehner. (2011) No need for a cognitive map: decentralized memory for insect navigation. PLoS Comput. Biol 7 (3): e1002009.

Darwin C. (1859) The origin of species by means of natural selection or the preservation of favoured races in the struggle for life. Murray,J., London.

Duer A., B.H. Paffhausen, R. Menzel. (2015) High order neural correlates of social behavior in the honeybee brain. Journal of neuroscience methods $254: 1-9$. 
Dujardin. (1850) Memoire sur le systeme nerveux des insects. Ann Sci Nat Zool 14: 195-206.

Dyer F.C., J.L. Gould. (1981) Honey bee orientation: A backup system for cloudy days. Science 214 : 10411042.

Eckstein M.P., S.C. Mack, D.B. Liston, L. Bogush, R. Menzel, et al. (2013) Rethinking human visual attention: Spatial cueing effects and optimality of decisions by honeybees, monkeys and humans. Vision research $85: 5-19$

Filla I., R. Menzel. (2015) Mushroom body extrinsic neurons in the honeybee (Apis mellifera) brain integrate context and cue values upon attentional stimulus selection. J Neurophysiol 114 : 2005 - 2014.

Fisher Y.E., J. Lu, I. D’Alessandro, R.I. Wilson. (2019) Sensorimotor experience remaps visual input to a heading-direction network. Nature: 1-5.

Forel A. (1910) Das Sinnesleben der Insekten. Reinhardt, Muenchen.

Frisch K.v. (1953) 'Sprache'oder 'Kommunikation'der Bienen?“. Psychologische Rundschau 4 : 235-236.

Giurfa M. (2003) Cognitive neuroethology: dissecting nonelemental learning in a honeybee brain. Curr. Opin. Neurobiol 13 (6): 726-735.

Giurfa M., J.-C. Sandoz. (2012) Invertebrate learning and memory: fifty years of olfactory conditioning of the proboscis extension response in honeybees. Learning \& memory 19(2): 54-66.

Giurfa M., B. Eichmann, R. Menzel. (1996) Symmetry perception in an insect. Nature 382 : 458-461.

Giurfa M., S.W. Zhang, A. Jenett, C. Boenisch, C. Wiley, et al. (2001) The concepts of sameness and difference in an insect. Proceedings of the 28th Göttingen Neurobiology Conference, Göttingen, June 2001: 685.

Hammer M., R. Menzel. (1995) Learning and memory in the honeybee. J. Neurosci 15(3): 1617-1630.

Homberg U., S. Heinze, K. Pfeiffer, M. Kinoshita, J.B. el. (2011) Central neural coding of sky polarization in insects. Philos. Trans. R. Soc. Lond B Biol Sci 366 (1565): 680-687.

Hull C.L. (1943) Principles of behaviour. Appleton-Century-Crofts, New York.

Jack-McCollough R.T., J.C. Nieh. (2015) Honeybees tune excitatory and inhibitory recruitment signalling to resource value and predation risk. Animal Behaviour 110 : $9-17$.

Jamieson D., M. Bekoff. (1996) On aims and methods of cognitive ethology. Readings in animal cognition: 65-77.

Joerges J., A. Küttner, C.G. Galizia, R. Menzel. (1997) Representation of odours and odour mixtures visualized in the honeybee brain. Nature 387 : 285-288.

Kenyon F.C. (1896) The brain of the bee - A preliminary contribution to the morphology of the nervous system of the Arthropoda. Journal of Comparative Neurology 6: 134-210.

Krain A.L., A.M. Wilson, R. Arbuckle, F.X. Castellanos, M.P. Milham. (2006) Distinct neural mechanisms of risk and ambiguity: a meta-analysis of decision-making. Neuroimage 32 (1): 477-484.

Kuwabara M. (1957) Bildung des bedingten Reflexes von Pavlovs Typus bei der Honigbiene, Apis mellifica. J. Fac. Sci. Hokkaido Univ. Ser. VI Zool 13 : 458-464.

Lehrer M. (1991) Bees Which Turn Back and Look. Naturwiss 78 : 274-276.

Mackintosh N., N.J. Mackintosh. (2011) IQ and human intelligence. Oxford University Press.

Maeterlinck M. (1901) The life of the bee. Dodd, Mead.

Matsumoto Y., R. Menzel, J.C. Sandoz, M. Giurfa. (2012) Revisiting olfactory classical conditioning of the proboscis extension response in honey bees: a step toward standardized procedures. J Neurosci Methods 211 (1): 159-167.

Menzel R. (2012) The honeybee as a model for understanding the basis of cognition. Nature reviews. Neuroscience 13 (11): 758-768

Menzel R. (2014) The insect mushroom body, an experience-dependent recoding device. Journal of Physiology-Paris 108(2): 84-95.

Menzel R (2017a) Search Strategies of Intentionality in the Honeybee Brain, In: Byrne J.H. (2017) The Oxford handbook of invertebrate neurobiology. Oxford University Press., pp 1-37

Menzel R. (2017b) Navigation and Communication in Insects, in: Chief J.H.B.E.I. (Ed.), Learning and Memory: A Comprehensive Reference (Second Edition), Elsevier, Amsterdam, New York, London,, pp. 389405.

Menzel R. (2019) The Waggle Dance as an Intended Flight: A Cognitive Perspective. Insects 10 (12): 424.

Menzel R., J. Fischer. (2011) Animal thinking: contemporary issues in comparative cognition. MIT press.

Menzel R., M. Giurfa. (2006a) Dimensions of Cognition in an Insect, the Honeybee. Behavioral and Cognitive Neuroscience Reviews 5 : 24-40.

Menzel R., M. Giurfa. (2006b) Dimensions of Cognition in an Insect, the Honeybee. Behavioral and Cognitive Neuroscience Reviews 5 : 24-40

Menzel R., U. Greggers, A. Smith, S. Berger, R. Brandt, et al. (2005) Honey bees navigate according to a maplike spatial memory. Proc. Natl. Acad. Sci U. S. A 102 (8): 3040-3045.

Menzel R., B. Brembs, M. Giurfa. (2007) Cognition in Invertebrates, in: Kaas J.H. (Ed.), Evolution of Nervous Systems, Vol. II: Evolution of Nervous Systems in Invertebrates, Academic Press, Oxford, pp. 403-422.

Menzel R., A. Kirbach, W.-D. Haass, B. Fischer, J. Fuchs, et al. (2011) A common frame of reference for learned and communicated vectors in honeybee navigation. Curr Biol 21 (8): 645-650.

Nieh, J.C. (2010) A negative feedback signal that is triggered by peril curbs honey bee recruitment. Curr. Biol. 20 (4), 310-315

O'Keefe J., J. Nadel. (1978) The hippocampus as a cognitive map. Oxford U. Press, New York. 
Opfinger E. (1931) Über die Orientierung der Biene an der Futterquelle. Z. vergl. Physiol 15 : 432-487.

Paffhausen B.H., I. Fuchs, A. Duer, I. Hillmer, I.M. Dimitriou, et al. (2020) Neural correlates of social behavior in mushroom body extrinsic neurons of the honeybee Apis mellifera. Frontiers in Behavioral Neuroscience 14 .

Rensch B. (1954) The relation between the evolution of central nervous functions and the body size of animals. Evolution as a process: 181-200.

Rescorla R.A., A.R. Wagner. (1972) A theory of classical conditioning: variations in the effectiveness of reinforcement and non-reinforcement, in: Black A.H. and Prokasy W.F. (Eds.), Classical conditioning II: Current research and theory, Appleton-Century-Crofts, New York, pp. 64-99.

Rollin B.E. (1990) How the animals lost their minds: Animal mentation and scientific ideology. Interpretation and explanation in the study of animal behavior $1: 375-393$.

Romanes G.J. (1883) Animal intelligence. D. Appleton.

Schultz W. (2006) Behavioral theories and the neurophysiology of reward. Annual Review of Psychology 57 : 87-115.

Seeley T.D., P.K. Visscher, T. Schlegel, P.M. Hogan, N.R. Franks, et al. (2012) Stop signals provide cross inhibition in collective decision-making by honeybee swarms

Seelig J.D., V. Jayaraman. (2015) Neural dynamics for landmark orientation and angular path integration. Nature 521 (7551): 186.

Skinner B.F. (1938) The behavior of organisms. AppletonCentury-Crofts, New York.

Skinner B.F. (1988) The selection of behavior: The operant behaviorism of BF Skinner: Comments and consequences. CUP Archive.

Sprengel C.K. (1793) Das entdeckte Geheimnis der Natur im Bau und in der Befruchtung der Blumen, Berlin.

Szyszka P., A. Galkin, R. Menzel. (2008) Associative and non-associative plasticity in Kenyon cells of the honeybee mushroom body. frontiers in Systems Neuroscience 2 : 1-10.

Thorpe W.H. (1979) Origins and rise of ethology. Heinemann Educational Books.

Tinbergen N. (1951) The study of instinct.

Tolman E.C. (1948) Cognitive maps in rats and men. Psychol. Rev 55: 189-208.

Tolman E.C. (1990) Cognitive maps in rats and men, in: Shaw G.L., McGaugh, J.L., Rose, S.P. (Ed.),
Neurobiology of learning and memory, World Scientific, Singapore, pp. 67-86.

Vareschi E. (1971) Duftunterscheidung bei der Honigbiene - Einzelzell-Ableitungen und Verhaltensreaktionen. Z. vergl. Physiol 75 : 143-173.

von Frisch K. (1905) Methoden sinnesphysiologischer und psychologischer Untersuchungen an Bienen. Handbuch der biol. Arbeitsmethoden Abt.VI, Teil D: 9-177.

von Frisch K. (1914) Der Farbensinn und Formensinn der Biene. Zool. Jb. Physiol 37 : 1-238.

von Frisch K. (1919) Über den Geruchsinn der Biene und seine blütenbiologische Bedeutung. Zool. Jahrbücher 37: 2-238.

von Frisch K. (1959) Insekten - die Herren der Erde. Naturwiss. Rundschau 10 : 369-375.

Von Frisch K. (1962) Dialects in the language of the bees. Scientific American 207 (2): 78-89.

von Frisch K. (1967) The dance language and orientation of bees. Harvard Univ.Press, Cambridge.

von Frisch K. (2013) Erinnerungen eines Biologen. Springer-Verlag.

von Frisch K., M. Lindauer. (1954) Himmel und Erde in Konkurrenz bei der Orientierung der Bienen. Naturwiss 41 : 245-253.

Watson J.B. (1930) Der Behaviorismus [Behaviorism], Oxford: Deutsche Verlags-Anstalt.

Webb B. (2019) The internal maps of insects. Journal of Experimental Biology 222(Suppl 1): jeb188094.

Wilson D.A., R.J. Stevenson. (2003) Olfactory perceptual learning: the critical role of memory in odor discrimination. Neurosci Biobehav. Rev 27 (4): 307-328.

Zeil J. (1993) Orientation flights of solitary wasps (Cerceris; Specidae; Hymenoptera) I. Description of flight. J. Comp. Physiol. [A] 172 : 189-205.

Zeil J., A. Kelber, R. Voss. (1996) Structure and function of learning flights in ground-nesting bees and wasps. $\mathrm{J}$ Exp. Biol 199 (Pt 1): 245-252.

Zwaka H., R. Bartels, S. Lehfeldt, M. Jusyte, S. Hantke, et al. (2018) Learning and its neural correlates in a virtual environment for honeybees. Frontiers in behavioral neuroscience 12 : 279 .

Publisher's note Springer Nature remains neutral with regard to jurisdictional claims in published maps and institutional affiliations. 